Check for updates

Cite this: RSC Adv., 2019, 9, 40203

\title{
Syntheses, characterization and properties of three coordination polymers with interpenetrating structures comprising 4,4'-(1H-1,2,4-triazol-1-yl) methylene-bis(benzonic acid) $\uparrow$
}

\begin{abstract}
Lun Zhao, (D)* Lingshu Meng, Xin Liu, Guanlin Guo, Congcong Xiao and Haibing Liu
Three new coordination polymers (CPs), $\left\{[\mathrm{Pb}(\mathrm{tmdb})]\left(\mathrm{H}_{2} \mathrm{O}\right)\right\}_{n} \quad(1),\left\{\left[\mathrm{Zn}(\mathrm{tmdb})(\mathrm{bimb})_{0.5}\right]\right\}_{n} \quad$ (2) and $\left\{\left[\mathrm{Zn}_{3}(\mathrm{tmdb})_{3}(\mathrm{bpmb})_{1.5}\right]\left(\mathrm{H}_{2} \mathrm{O}\right)_{6}\right\}_{n}$ (3) $\left(\mathrm{H}_{2} \mathrm{tmdb}=4,4^{\prime}-(1 \mathrm{H}-1,2,4\right.$-triazol-1-yl)methylene-bis(benzonic acid), where bpmb =1,4-bis(pyridin-4-ylmethoxy)benzene and bimb =1,4-bis(imidazoly-1-yl)benzene), have been solvothermally or hydrothermally synthesized. Compound 1 is a $2 \mathrm{D}$ network with the point symbol $(4 \cdot 6 \cdot 8)\left(4 \cdot 6^{2}\right)$ and compound 2 is a 4 -fold interpenetrating $3 D$ network with spiral chains. The topological type of 2 is $d m c$ (topos\&RCSR.ttd) with the point symbol $\left(4 \cdot 8^{2}\right)\left(4 \cdot 8^{5}\right)$. Compound 3 is a 3 fold interpenetrating 3D network with the point symbol $\left(6^{3}\right)_{2}\left(8 \cdot 6^{5}\right)_{2}\left(10 \cdot 6^{2}\right)\left(8 \cdot 10 \cdot 6^{4}\right)$. The electrochemiluminescence (ECL) behaviors of 2 and 3 were studied. The applications of CP 2 and 3 in detecting ions were explored, and the results show that they can be used as fluorescent probes to selectively detect and identify $\mathrm{Fe}^{3+}$ ions in water. In addition, the applications of CP 2 and 3 in the adsorption and separation of dyes were researched. Furthermore, the gas adsorption of 3 was studied.
\end{abstract}

Received 19th October 2019

Accepted 20th November 2019

DOI: $10.1039 / c 9 r a 08559 a$

rsc.li/rsc-advances
However, scientists are not satisfied with the status quo and are focusing on bifunctional mixed-tooth ligands with abundant coordination patterns and potential active sites. For example, Bharadwaj and colleagues selected a ligand $4-(1 H$ imidazole-1-yl)benzoic acid (HIBA) with an imidazole/ benzimidazole and a carboxylate donor at the end to explore the transition metal (Cd, $\mathrm{Cu}, \mathrm{Zn}$ ) structure of the compound. ${ }^{2}$ $\mathrm{Yu}$ and his group used the ligand [3,5-di(4H-1,2,4-triazol-4-yl) benzoato] to explore the formation of nitrate, chloride and sulfate with metallic cobalt. ${ }^{3}$ Mao and colleagues used five predesigned synthetic bifunctional mixed ligands, 4-\{bis(4-benzoic)amino\}-4H-1,2,4-triazole, to form five new CPs, and the luminescence or magnetic properties of the compounds were studied accordingly. ${ }^{4}$ Among the compounds constructed from the above bifunctional mixed-tooth ligands, only the bifunctional mixed-tooth ligands and the solvent molecules participate in the coordination, and they do not contain the second organic ligand. However, Zheng and his group utilized the $\mathrm{N}$ center polydentate pyridine-carboxylate bifunctional ligand 4,4'-((4-(pyridin-4-yl)phenyl)azanediyl)dibenzoic acid, with different contents. Nitrogen ligands construct a compound of metallic Co and $\mathrm{Zn}$, which can be used for the gas separation of $\mathrm{CO}_{2}$ and $\mathrm{CH}_{4}{ }^{5}$

In addition, mixed-ligand CPs have become an important type of CP because they can incorporate more types of organic ligands into a single unique framework, which may deliver some new functions derived from organic ligands. ${ }^{6,7}$ The combination of nitrogen donor ligands and aromatic

\footnotetext{
China. E-mail: zhaolun7511@126.com; Tel: +86-431-86168903

$\dagger$ Electronic supplementary information (ESI) available: Selected bond lengths and angles, simulated and experimental X-ray powder diffraction patterns, TGA curves, UV-vis absorption spectra and X-ray crystallographic files in cif format. CCDC 1947245, 1947250 and 1947261 contain the supplementary crystallographic data for compounds 1-3 respectively. For ESI and crystallographic data in CIF or other electronic format see DOI: 10.1039/c9ra08559a
} 
carboxylate has been proven to be an effective and useful strategy for constructing diverse mixed-ligand CPs. ${ }^{8}$ However, the incorporation of an $\mathrm{N}$-containing carboxylate and carboxylate into a unique framework has been relatively less explored. To the best of our knowledge, multifunctional ligands have been extensively investigated owing to their versatile coordination modes and potential as hydrogen bond donors and acceptors. ${ }^{9} \quad$ Here, the 4,4'-(1H-1,2,4-triazol-1-yl)methylenebis(benzonic acid) ( $\mathrm{H}_{2}$ tmdb) ligand (Scheme 1) was chosen as the linker, for the following reasons: a flexible carboxyphenyl and a rigid triazolyl group can provide multidentate metalbinding sites and diverse coordination modes; the variable coordination modes of the ligands ${ }^{\mathbf{1 0 , 1 1}}$ ligands with difunctional groups. Moreover, the design and selection of organic ligands is of crucial concern in the construction of MOFs, because their molecular size, symmetry, coordination mode and functional groups are directly correlated with the architectures and applications of the MOFs.

In this article, we chose a bifunctional semi-rigid tripleligand $\mathrm{H}_{2}$ tmdb containing two flexible carboxyphenyl groups and a rigid triazolyl group as the main building block, and several metal-organic framework materials were prepared with transition metals and secondary nitrogen-containing ligands in hydrothermal/solvothermal conditions (Scheme 1). Their structures were determined by X-ray single crystal diffraction, and their properties were characterized by thermogravimetry, powder X-ray diffraction (PXRD) and fluorescence, etc.

\section{Experimental section}

\section{Materials and methods}

All solvents and reagents for synthesis were of reagent grade quality, bought from commercial sources and used as received. PXRD patterns were collected on a D2 PHASER A26-X1 XRD diffractometer. The IR spectra $\left(4000-400 \mathrm{~cm}^{-1}\right)$ were obtained from $\mathrm{KBr}$ pellets with an FTIR Nexus spectrophotometer. Elemental analyses were performed on a PerkinElmer $240 \mathrm{C}$ analyzer. Thermogravimetric analysis (TGA) curves were measured under air atmosphere at a heating rate of $10{ }^{\circ} \mathrm{C} \mathrm{min}^{-1}$ on a PerkinElmer TG-7 thermal analyzer. The fluorescence spectra were recorded on a HITACHI F-7000 Spectrometer. $^{12}$ ECL signals were monitored and recorded by an MPI-B ECL analyzer (Xi'an Remax Electronic Science and Technology Co. Ltd, Xi'an, China, with the voltage of the photomultiplier tube set at $600 \mathrm{~V}$ and the potential scan from -0.8 to $0.8 \mathrm{~V}$ at a scanning rate of $0.1 \mathrm{~V} \mathrm{~s}^{-1}$. UV-vis adsorption spectra were collected on a Cary 300 spectrophotometer. $\mathrm{CO}_{2}$ and $\mathrm{CH}_{4}$ adsorption measurements (up to 1 bar) were carried out on an Autosorb-3.0 (Quantachrome) volumetric analyzer. ${ }^{13}$

\section{Synthesis of $\left\{[\mathrm{Pb}(\mathbf{t m d b})]\left(\mathrm{H}_{2} \mathrm{O}\right)\right\}_{n}(1)$}

A mixture of $\mathrm{Pb}\left(\mathrm{NO}_{3}\right)_{2} \cdot 6 \mathrm{H}_{2} \mathrm{O}(33.1 \mathrm{mg}, 0.1 \mathrm{mmol})$ and $\mathrm{H}_{2} \mathrm{tmdb}$ (32.3 mg, $0.1 \mathrm{mmol}$ ), was dissolved in $10 \mathrm{~mL}$ of $\mathrm{H}_{2} \mathrm{O}$ solvent. After stirring, the mixture was sealed in a $25 \mathrm{~mL}$ Parr Teflonlined stainless steel autoclave under autogenous pressure and heated at $160{ }^{\circ} \mathrm{C}$ for $72 \mathrm{~h}$. Then after slow cooling to room temperature at $20{ }^{\circ} \mathrm{C} \mathrm{h}^{-1}$, large quantities of colorless bulk crystals were obtained and the crystals were filtered off, washed with absolute ethyl alcohol, and dried under ambient conditions. The yield of the reaction was $56 \%$ based on $\mathrm{H}_{2}$ tmdb. Elemental analysis calcd for $\mathrm{C}_{17} \mathrm{H}_{11} \mathrm{~N}_{3} \mathrm{O}_{5} \mathrm{~Pb}(\%)$ : $\mathrm{C}, 38.01 ; \mathrm{H}$, 2.11; N, 7.65. Found: C, 37.50; H, 2.04; N, 7.72. FT-IR (4000$\left.400 \mathrm{~cm}^{-1}\right): \quad 3231(\mathrm{~s}), \quad 2926(\mathrm{~s}), \quad 1654(\mathrm{~m}), \quad 1540(\mathrm{~m}), 1391(\mathrm{w})$, 1273(m), 1133(m), 1007(s), 963(s), 835(s), 777(m), 644(s), 531(s), 496(s).

\section{Synthesis of $\left\{\left[\mathrm{Zn}(\operatorname{tmdb})(\mathrm{bimb})_{0.5}\right]\right\}_{n}$ (2)}

A mixture of $\mathrm{Zn}\left(\mathrm{NO}_{3}\right)_{2} \cdot 6 \mathrm{H}_{2} \mathrm{O}(29.7 \mathrm{mg}, 0.1 \mathrm{mmol}), \mathrm{H}_{2} \mathrm{tmdb}$ (32.3 $\mathrm{mg}, 0.1 \mathrm{mmol}$ ), and bimb (21.1 $\mathrm{mg}, 0.1 \mathrm{mmol})$, was<smiles>O=C(O)c1ccc(C(c2ccc(C(=O)O)cc2)n2cncn2)cc1</smiles>

4,4'- (1H-1,2,4-triazol-1-yl) methylene-dibenzoic acid( $\left.\mathrm{H}_{2} \mathrm{tmdb}\right)$

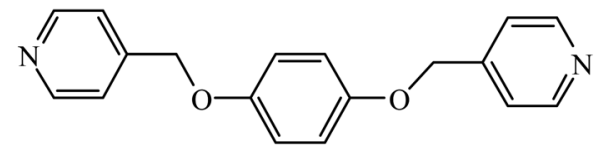

1,4-bis(pyridin-4-ylmethoxy)benzene (bpmb)

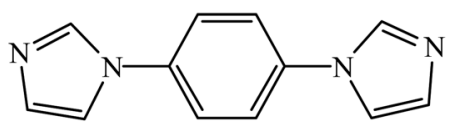

1,4-bis(imidazoly-1-yl)benzene (bimb)

Scheme 1 Molecular structure of the ligands. 
dissolved in $10 \mathrm{~mL}$ of $\mathrm{H}_{2} \mathrm{O}$ solvent. After stirring, the mixture was sealed in a $25 \mathrm{~mL}$ Parr Teflon-lined stainless steel autoclave under autogenous pressure and heated at $160{ }^{\circ} \mathrm{C}$ for $72 \mathrm{~h}$. Then after slow cooling to room temperature at $20{ }^{\circ} \mathrm{C} \mathrm{h}^{-1}$, large quantities of colorless bulk crystals were obtained and the crystals were filtered off, washed with absolute ethyl alcohol, and dried under ambient conditions. The yield of the reaction was $62 \%$ based on $\mathrm{H}_{2}$ tmdb. Elemental analysis calcd for $\mathrm{C}_{23} \mathrm{H}_{15} \mathrm{~N}_{5} \mathrm{O}_{4} \mathrm{Zn}(\%): \mathrm{C}, 56.19 ; \mathrm{H}, 3.12 ; \mathrm{N}, 14.21$. Found: C, 56.28; $\mathrm{H}, 3.08 ; \mathrm{N}, 14.27$. FT-IR (4000-400 $\left.\mathrm{cm}^{-1}\right): 3438(\mathrm{~s}), 3102(\mathrm{~s})$, 1608(w), 1527(m), 1374(w), 1135(m), 1074(m), 994(s), 964(s), 837(m), 774(w), 650(m), 542(s).

\section{Synthesis of $\left\{\left[\mathrm{Zn}_{3}(\mathrm{tmdb})_{3}(\mathrm{bpmb})_{1.5}\right]\left(\mathrm{H}_{2} \mathrm{O}\right)_{6}\right\}_{n}(3)$}

A mixture of $\mathrm{Zn}\left(\mathrm{NO}_{3}\right)_{2} \cdot 6 \mathrm{H}_{2} \mathrm{O}(29.7 \mathrm{mg}, 0.1 \mathrm{mmol}), \mathrm{H}_{2} \mathrm{tmdb}$ (32.3 mg, $0.1 \mathrm{mmol}$ ), and bpmb (29.6 mg, $0.1 \mathrm{mmol})$, was dissolved in $10 \mathrm{~mL}$ of $\mathrm{DMF}-\mathrm{H}_{2} \mathrm{O}$ (with a volume ratio of $8: 2$ ) mixed solvent. After stirring, the mixture was sealed in a $25 \mathrm{~mL}$ Parr Teflon-lined stainless steel autoclave under autogenous pressure and heated at $80{ }^{\circ} \mathrm{C}$ for $72 \mathrm{~h}$. Then after slow cooling to room temperature at $20{ }^{\circ} \mathrm{C} \mathrm{h}^{-1}$, large quantities of colorless bulk crystals were obtained and the crystals were filtered off, washed with absolute ethyl alcohol, and dried under ambient conditions. The yield of the reaction was $60 \%$ based on $\mathrm{H}_{2} \mathrm{tmdb}$. Elemental analysis calcd for $\mathrm{C}_{78} \mathrm{H}_{57} \mathrm{Zn}_{3} \mathrm{~N}_{12} \mathrm{O}_{15}$ (\%): C, 58.53; $\mathrm{H}$, 3.65; N, 10.54. Found: C, 58.60; H, 3.59; N, 10.51. FT-IR (4000$\left.400 \mathrm{~cm}^{-1}\right): 3425(\mathrm{~s}), 3120(\mathrm{~s}), 1609(\mathrm{w}), 1506(\mathrm{~m}), 1378(\mathrm{w}), 1228(\mathrm{~m})$, 1134(m), 1018(s), 997(s), 826(m), 773(m), 650(s), 574(s), 491(s).

\section{Crystallographic data collection and refinement}

Single crystals of suitable size were placed on a Bruker SMART APEXIICCD diffractometer, and the incident light source was provided by Mo $\mathrm{K} \alpha$ rays $(\lambda=0.71073 \AA)$ monochromated by a graphite monochromator, and the diffraction point was collected at $296 \mathrm{~K}$ in $\omega$ scan mode. Absorption correction was performed using the SAINT and SADABS procedures, and all the crystal structures were solved by the direct method using SHELXS97. ${ }^{14}$ All non-H atoms were anisotropically processed. The measured crystallographic data are shown in Table S1. $\uparrow$ Selected bond lengths and angles are listed in Table S2 (in the ESI $\dagger$ ).

\section{Results and discussion}

\section{Crystal structure of (1)}

Compound 1 crystallized in a monoclinic space group $C 2 / c$, and it contains one independent $\mathrm{Pb}$ (II) cation, one $\mathrm{tmdb}^{2-}$ ligand and one free $\mathrm{H}_{2} \mathrm{O}$ molecule (Fig. 1a). In asymmetrical structural units, the $\mathrm{Pb}$ (II) ion is four-connected by three oxygen atoms of the $\mathrm{tmdb}^{2-}$ ligands and one $\mathrm{N}$ atom of the $\mathrm{tmdb}^{2-}$ ligands, showing a plane tetrahedral geometry.

Two carboxyl groups of the $\mathrm{tmdb}^{2-}$ are bridged to the $\mathrm{Pb}$ (II) ion by monodentate and bidentate coordination, respectively. The distances between the $\mathrm{Pb}-\mathrm{O}$ and the $\mathrm{Pb}-\mathrm{N}$ bonds range from 2.355(2) to 2.553(2) $\AA$ and 2.568(3) $\AA$, respectively. As shown in Fig. 1c, the $\mathrm{Pb}$ ion is bonded to the carboxylic acid ligand $\mathrm{tmdb}^{2-}$, and a $2 \mathrm{D}$ skeleton structure with double interspersion is formed. The $\mathrm{tmdb}^{2-}$ ligand is regarded as a 3connected node, the metal center is regarded as a 3-connected node, and the topological structure with the point symbol $(4 \cdot 6 \cdot 8)\left(4 \cdot 6^{2}\right)$ of compound 1 is as shown in Fig. 1 d.

\section{Crystal structure of (2)}

Compound 2 crystallized in a monoclinic space group $P 2_{1} / c$, and contains one independent $\mathrm{Zn}$ (II) cation, one $\mathrm{tmdb}^{2-}$ ligand and half a bimb ligand (Fig. 2a). In asymmetrical structural units, the $\mathrm{Zn}$ (II) ion is four-connected by two oxygen atoms of the $\mathrm{tmdb}^{2-}$ ligands and two $\mathrm{N}$ atoms of the $\mathrm{tmdb}^{2-}$ ligands and bimb ligands, showing a plane tetrahedral geometry. Only one carboxyl group of the $\mathrm{tmdb}^{2-}$ is bridged with an $\mathrm{Zn}$ (II) ion by monodentate coordination. The distances between the $\mathrm{Zn}-\mathrm{O}$ and $\mathrm{Zn}-\mathrm{N}$ bonds range from 1.948(7) to 1.984(9) $\AA$ and from 2.005(6) to 2.029(7) ^, respectively.

As shown in Fig. 2b, the carboxyl group and imidazole of the carboxylic acid $\mathrm{tmdb}^{2-}$ are respectively bonded to adjacent $\mathrm{Zn}$ (II) ions to form a 2D layer. Then the structure is joined by a nitrogen-containing ligand bimb to form a 3D supramolecular network structure (Fig. 2c). The tmdb ${ }^{2-}$ ligand is regarded as a 3-connected node, and the metal center is regarded as a 4connected node (Fig. 2d). The topological type of 2 is $\boldsymbol{d m c}$ (topos\&RCSR.ttd) with the point symbol $\left(4 \cdot 8^{2}\right)\left(4 \cdot 8^{5}\right)$. Due to the singularity of the spatial network structure, the four identical 3D network structures are interspersed with each other to form a quadruple-penetrating mesh structure (Fig. 2f). Furthermore, there are two interlaced left or right handed double helical chains (labeled L and R) in this frame, and two 1D chains are formed by [-Zn tmdb-] (Fig. 2e).

\section{Crystal structure of (3)}

Compound 3 crystallized in a monoclinic space group $P 2_{1} / c$, and it contains three independent $\mathrm{Zn}$ (II) cations, three $\mathrm{tmdb}^{2-}$ ligands, one and a half bpmb ligands and six free $\mathrm{H}_{2} \mathrm{O}$ molecules (Fig. 3a). In asymmetrical structural units, three $\mathrm{Zn}$ (II) ions are four-connected by two oxygen atoms of the $\mathrm{tmdb}^{2-}$ ligands and two $\mathrm{N}$ atoms of the $\mathrm{tmdb}^{2-}$ ligands and bimb ligands, showing a plane tetrahedral geometry (Fig. 3b).

Only one carboxyl group of the tmdb ${ }^{2-}$ is bridged with $\mathrm{Zn}$ (II) ion by monodentate coordination. The distances between $\mathrm{Zn}-\mathrm{O}$ bonds and $\mathrm{Zn}-\mathrm{N}$ bonds range from 1.903(10) to 1.970(10) $\AA$ and from $1.977(12)$ to $2.027(14) \AA$, respectively. The carboxyl group and imidazole of the carboxylic acid $\mathrm{tmdb}^{2-}$ are respectively bonded to adjacent $\mathrm{Zn}$ (II) ions to form a 2D layer by inverting the connection (Fig. 3c). Then the structure is joined by a nitrogencontaining ligand bimb to form a 3D supramolecular network structure (Fig. 3d). The tmdb ${ }^{2-}$ ligand is regarded as a 3-connected node, the metal center is regarded as a 4-connected node, and the topological structure with the point symbol $\left(6^{3}\right)\left(8 \cdot 6^{5}\right)\left(6^{3}\right)\left(8 \cdot 6^{5}\right)\left(10 \cdot 6^{2}\right)\left(8 \cdot 10 \cdot 6^{4}\right)$ of compound 3 is as shown in Fig. 3e. According to the analysis, the two identical $3 \mathrm{D}$ network structures are interspersed with each other to form a double interspersed network structure, then another inverted 3D network structure interspersed with each other to form a triple-penetrating mesh structure (Fig. 3f). 
(a)

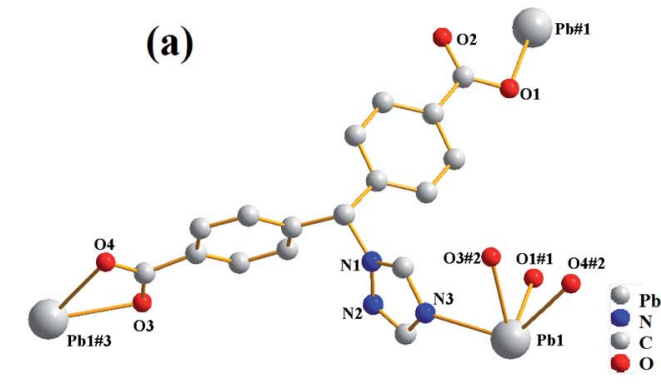

(b)

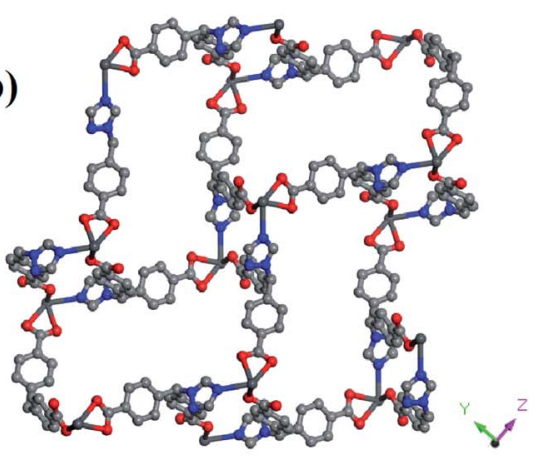

(c)

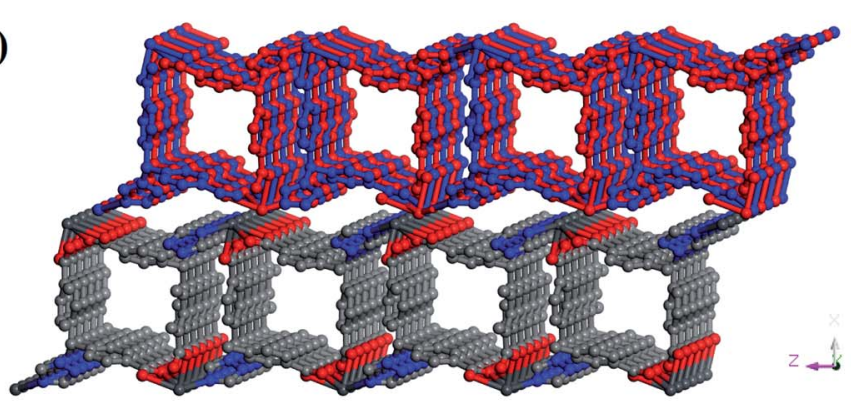

(d)

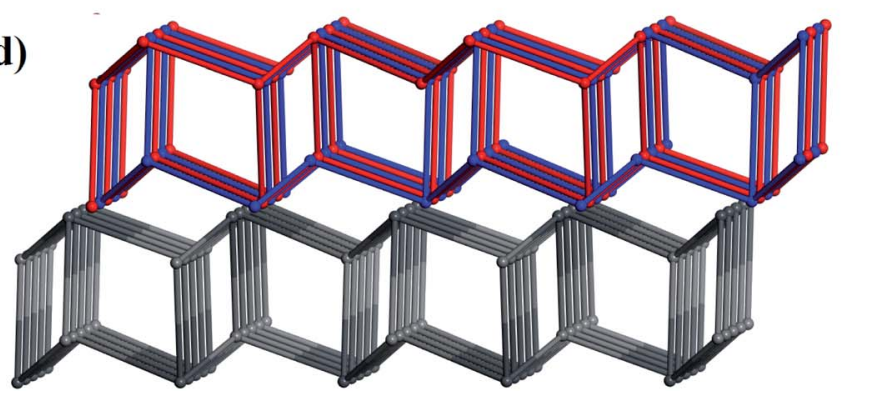

Fig. 1 (a) The coordination environment for $\mathrm{Pb}(॥)$ in 1. (b) 2D layered structure of 1. (c) Double layered structure of 1. (d) 3D network topology representation of 1 .

\section{PXRD and thermogravimetric analysis (TGA)}

The PXRD patterns of the experimental data 1-3 were in good agreement with the corresponding simulated ones, illustrating the purity of compounds 1-3 (ESI, Fig. S1-S3†).

TGA experiments were performed from 20 to $800{ }^{\circ} \mathrm{C}$ with a heating rate of $10^{\circ} \mathrm{C} \mathrm{min}^{-1}$ under air atmosphere to evaluate the thermal stabilities of the three compounds (ESI, Fig. S4 $\dagger$ ). For 1, the weight loss of the first stage was attributed to the release of free $\mathrm{H}_{2} \mathrm{O}$ molecules in the range of $25-150{ }^{\circ} \mathrm{C}$ (obsd $2.76 \%$, calcd $3.30 \%$ ). Then it continuously lost weight due to the collapse of the frameworks. The final residue was $\mathrm{PbO}$ (obsd $40.96 \%$, calcd $38.12 \%$ ). For 2 , between 25 and $360{ }^{\circ} \mathrm{C}$ there was a slow weight loss. Then it continuously lost weight after $360^{\circ} \mathrm{C}$, probably due to the thermal decomposition of the ligand bimb and the collapse of the frameworks. The framework was stable up to $c a .530{ }^{\circ} \mathrm{C}$. The remaining weight corresponds to the formation of $\mathrm{ZnO}$ (obsd $17.27 \%$, calcd $16.58 \%$ ). For 3 , at $280^{\circ} \mathrm{C}$ there was a slow weight loss, then a drastic fall, probably due to the thermal decomposition of the ligand bimb and the collapse of the frameworks. The final residue was $\mathrm{ZnO}$ (obsd $13.62 \%$, calcd $15.27 \%)$.

\section{Photoluminescence properties of 2 and 3}

The luminescence properties of compounds $2,3, \mathrm{H}_{2} \mathrm{tmdb}$ and bimb were measured at room temperature, and the resulting spectra are shown in Fig. 4. Compound 2 had an emission peak at $420 \mathrm{~nm}\left(\lambda_{\mathrm{ex}}=317 \mathrm{~nm}\right), 3 \mathrm{had}$ a maximum emission peak at $451 \mathrm{~nm}\left(\lambda_{\mathrm{ex}}=367 \mathrm{~nm}\right)$, and that of ligand bimb was at $400 \mathrm{~nm}\left(\lambda_{\mathrm{ex}}\right.$ $=335 \mathrm{~nm})$, and that of ligand $\mathrm{H}_{2} \mathrm{tmdb}$ was at $432 \mathrm{~nm}\left(\lambda_{\mathrm{ex}}=338\right.$ $\mathrm{nm})$. The central metals of 2 and 3 were $\mathrm{Zn}^{2+}$ ions, and the outermost electron arrangement was a stable $\mathrm{d}^{10}$ configuration, which was not easily oxidized and reduced in the framework. ${ }^{15}$ Their excitation wavelength and emission wavelength are similar to those of ligand $\mathrm{H}_{2} \mathrm{tmdb}$, indicating that their luminescence comes mainly from the ligand $\mathrm{H}_{2} \mathrm{tmdb}$, and belongs to the electronic transition emission of $\pi^{*} \rightarrow \pi$ between ligands. Compared with the emission of the ligand $\mathrm{H}_{2} \mathrm{tmdb}$, significant blue shifts were observed for 2 , which might be assigned to ligands coordinated with $\mathrm{Zn}(\mathrm{II})$.

\section{ECL behaviors of 2 and 3}

Luminol is a luminescent reagent that produces an ECL signal in alkaline solution. $5 \mathrm{mg}$ of 2,3 and carboxylic acid ligand 


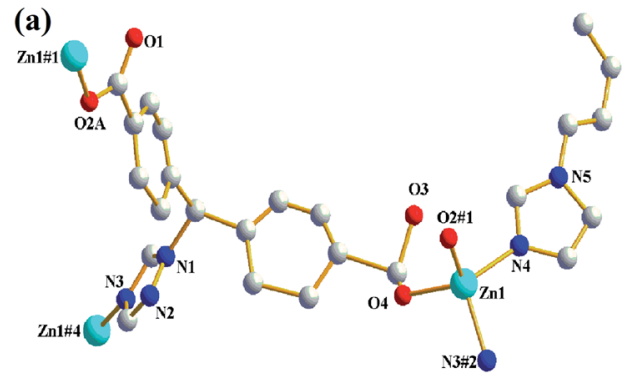

(c)

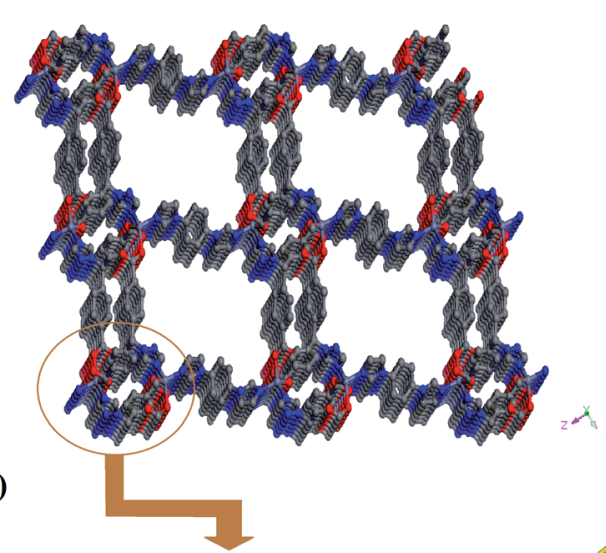

(b)

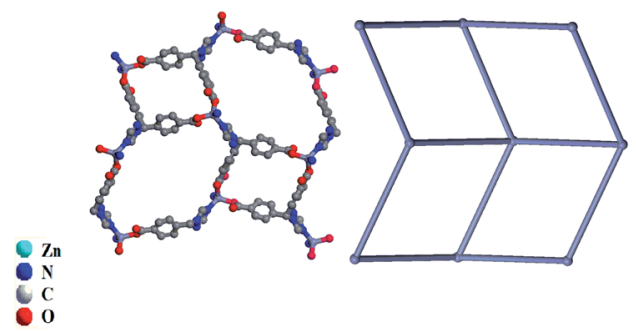

(d)

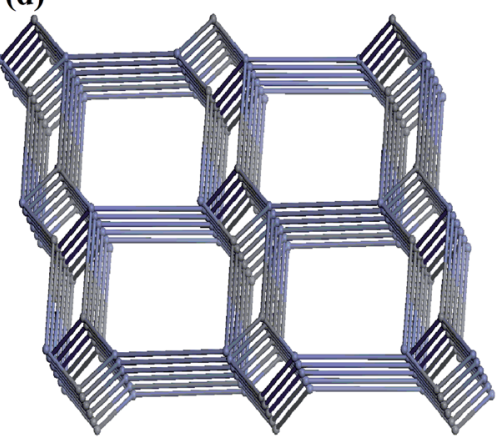

(f)
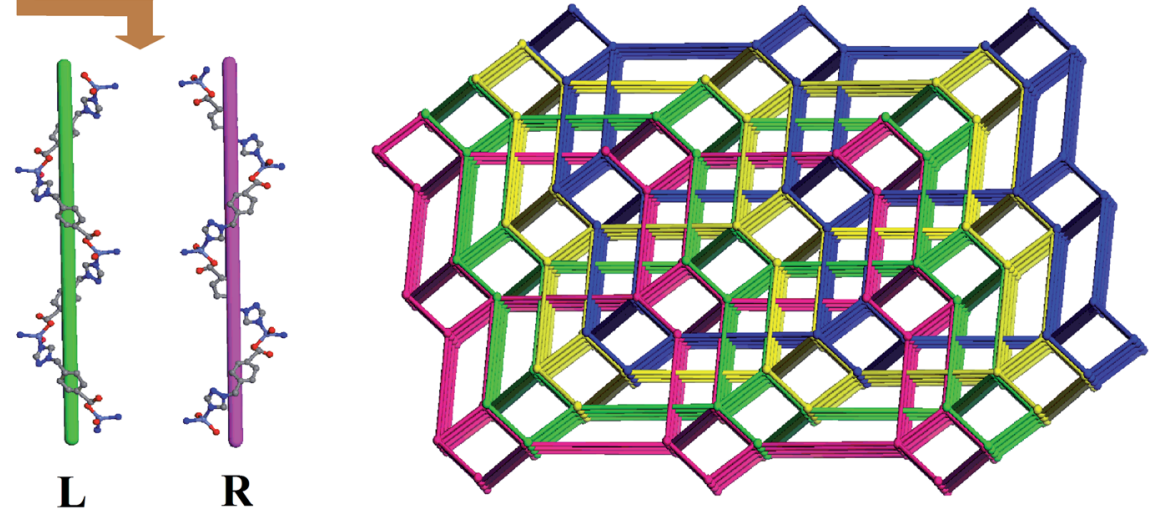

Fig. 2 (a) The coordination environment for $\mathrm{Zn}($ II) in 2. (b) View of 2D layered structure and 2D topology structure. (c) 3D network representation of 2. (d) 3D network topology representation of 2. (e) Schematic view of the double helix chains formed by Zn(॥) ions and tmdb ${ }^{2-}$ ligands. (f) View of quadruple-penetrating mesh topology structure.

$\mathrm{H}_{2} \mathrm{tmdb}$ were dispersed in $10 \mathrm{~mL}$ of water. After ultrasonic dispersion, $7 \mu \mathrm{L}$ of the mixed solution was added dropwise to the surface of the glassy carbon electrode, and then dried naturally. ECL scanning was performed in $5 \mathrm{~mL}$ of PBS $(0.1 \mathrm{M}$, $\mathrm{pH}=11)$ and $20 \mu \mathrm{L}$ of luminol solution $\left(25 \mathrm{mmol} \mathrm{L}^{-1}\right)$. As shown in Fig. 5, due to the poor conductivity of the carboxylic acid ligand $\mathrm{H}_{2}$ tmdb, it had an inhibitory effect on the ECL signal of luminol compared with GCE. However, 2 and 3 had a significant sensitizing effect on the ECL signal, in which the signal values of 3 were twice those of the bare electrode, and those of 2 could be up to 3 times as high.

When the compound-modified electrode was placed in a mixed solution of luminol and an alkaline PBS buffer solution, some of the luminol solution entered the surface of the compound-modified electrode to interact with the compound by molecular diffusion. Luminol underwent an oxidation reaction in the alkaline solution, and an electron was generated to produce a luminol anion. Similarly, the compound-modified electrode lost an electron at the excitation voltage, producing a corresponding cation. The luminol anion was coupled to the compound cation to produce a complex in an excited state. When the complex in the excited state returned to the ground state, photons were released and energy was generated, thereby generating ECL, which sensitized the ECL of the luminol system. Taking 2 as an example, its possible luminescence mechanism was as follows:

$$
\begin{gathered}
\mathrm{LH}^{-}-\mathrm{e}^{-} \rightarrow \mathrm{LH}^{*} \rightarrow \mathrm{L}^{\mathrm{g}-}+\mathrm{H}^{+} \\
\mathbf{2}-\mathrm{e}^{-} \rightarrow \mathbf{2}^{\mathrm{g}+} \\
\mathrm{L}^{\mathrm{g}-}+\mathbf{2}^{\mathrm{g}^{+}} \rightarrow 2^{*}+\mathrm{L}
\end{gathered}
$$



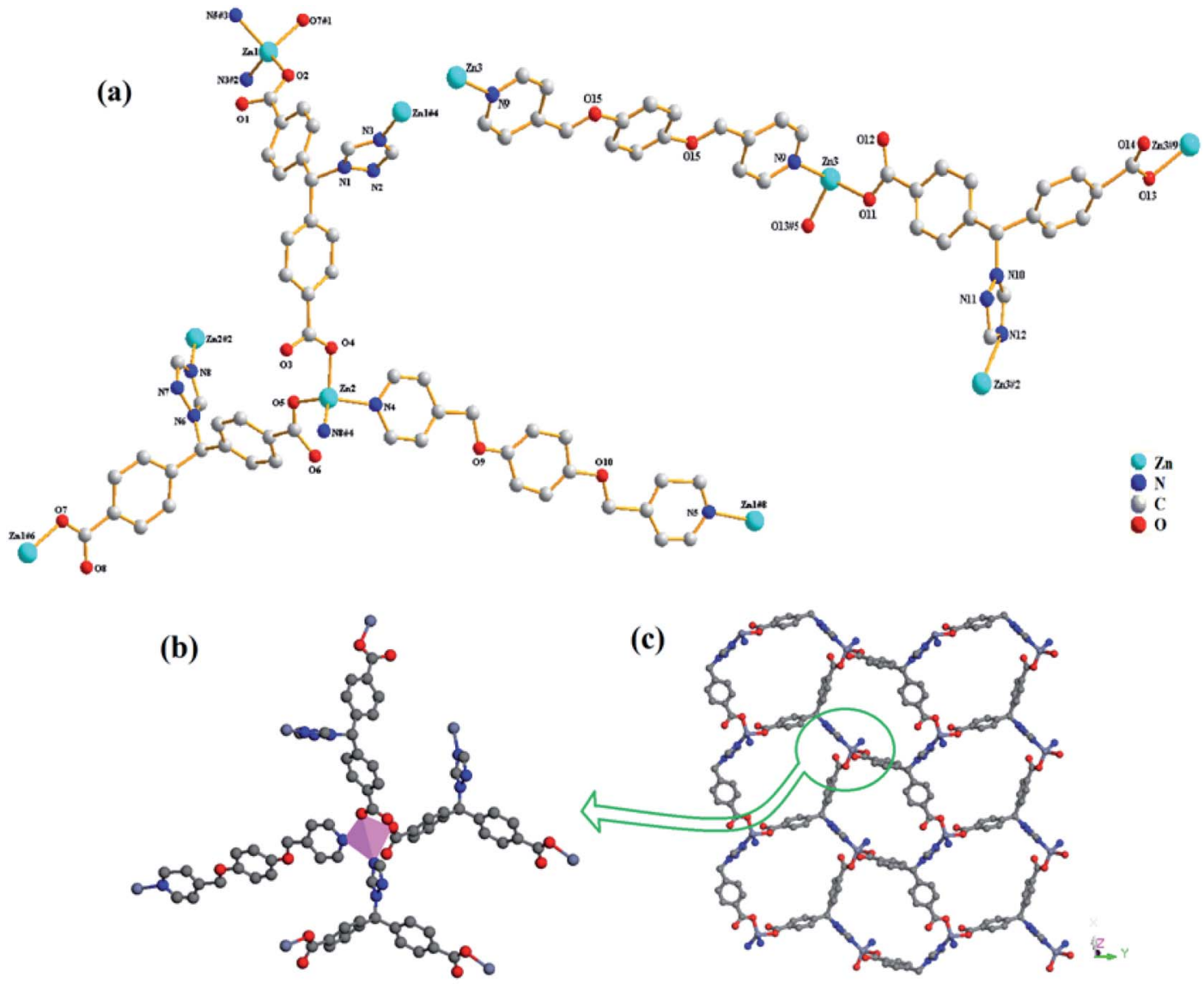

(d)

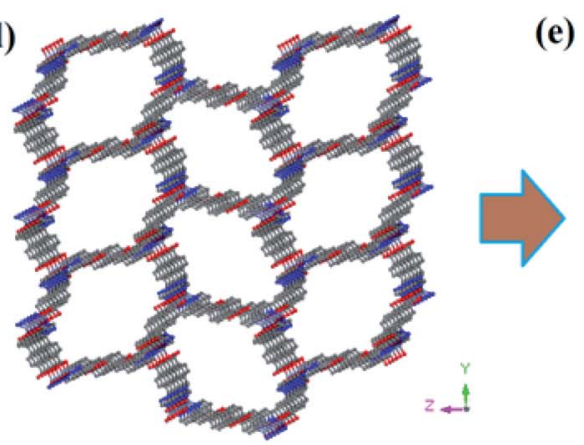

(e)

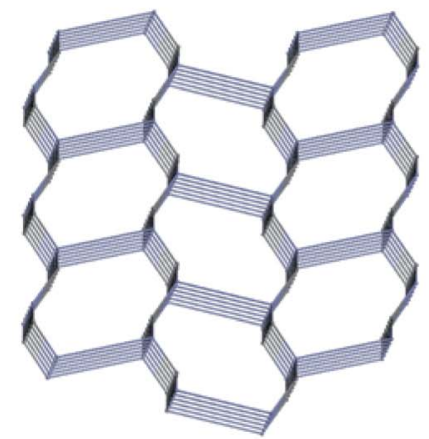

(f)

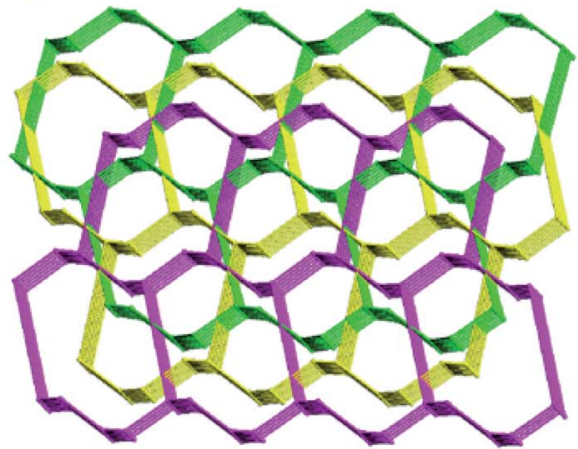

Fig. 3 (a) The coordination environment for $Z n$ (II) in 3. (b) View of four-connected Zn(II) ions. (c) 2D layered structure of 3. (d) 3D network representation of 3. (e) 3D network topology representation. (f) View of triple-penetrating mesh topology structure. 

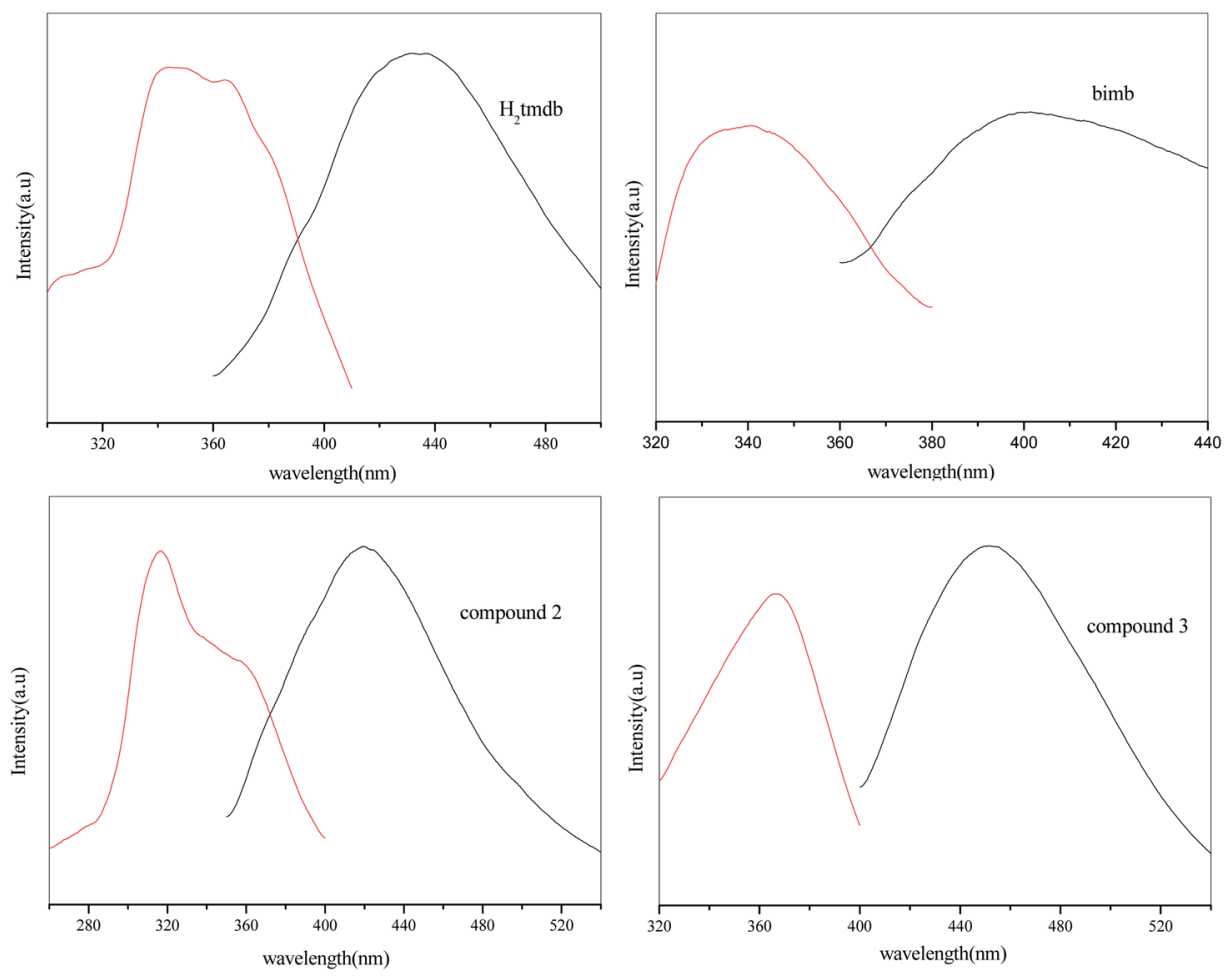

Fig. 4 Excited (red) and emission (black) spectra of compounds 2, 3, $\mathrm{H}_{2} \mathrm{tmdb}$ and bimb at room temperature.

$$
\mathbf{2}^{*} \rightarrow \mathbf{2}+h v
$$

Therefore, these compound-modified electrodes could be used as sensitizers for luminol in electrochemical detection.

\section{Selective sensing of cations}

Next, the fluorescence properties of compounds $\mathbf{2}$ and $\mathbf{3}$ were analyzed. Dispersions of $5 \mathrm{mg}$ of dry compounds 2 and 3 powder were added to $5 \mathrm{~mL}$ of metal nitrate aqueous solution (such as

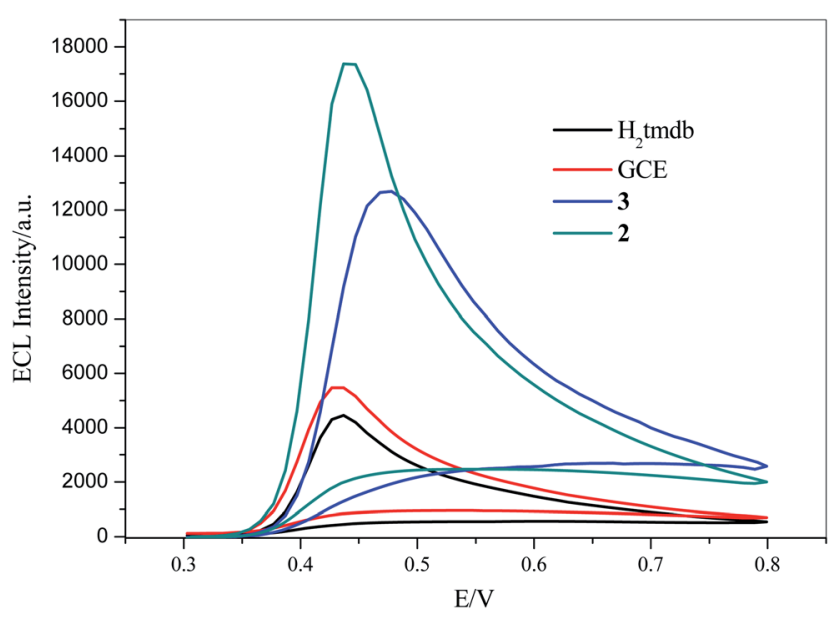

Fig. $5 \mathrm{ECL}$ of 2, 3, GCE and $\mathrm{H}_{2}$ tmdb in $0.1 \mathrm{M}$ PBS buffer $(\mathrm{pH}=11)$ and $25 \mathrm{mM}$ luminol solution, scan range: $-0.8 \mathrm{~V}$ to $0.8 \mathrm{~V}$, scan rate: $0.1 \mathrm{~V}$ $\mathrm{s}^{-1}$, respectively.
$\mathrm{Ag}^{+}, \mathrm{Ca}^{2+}, \mathrm{Na}^{+}, \mathrm{Cu}^{2+}, \mathrm{Fe}^{3+}, \mathrm{Cd}^{2+}, \mathrm{K}^{+}, \mathrm{Zn}^{2+}, \mathrm{Pb}^{2+}, \mathrm{Ni}^{2+}, \mathrm{Al}^{3+}, \mathrm{Cr}^{3+}$ and $\mathrm{Co}^{2+}$ ) with the concentration of ions being $1.0 \times$ $10^{-2} \mathrm{~mol} \mathrm{~L}^{-1}(\mathrm{M})$ by ultrasonication for about $30 \mathrm{~min}$, respectively, forming 2 and 3 @ $\mathrm{M}^{n+}$ stable suspensions.

The suspension of $\mathrm{Fe}^{3+}$ ions and $\mathrm{Cr}^{3+}$ ions in compounds 2 and 3 showed a significant quenching effect under ultraviolet irradiation at $365 \mathrm{~nm}$, but when we tested the fluorescence spectrum of the mixture, it had no effect. For 2 , the fluorescence intensities of the suspensions which added $\mathrm{Ca}^{2+}, \mathrm{Na}^{+}, \mathrm{Cu}^{2+}$, $\mathrm{Cd}^{2+}, \mathrm{Zn}^{2+}, \mathrm{Pb}^{2+}, \mathrm{Al}^{3+}$ and $\mathrm{Co}^{2+}$ cations were increased slightly, but the addition of $\mathrm{Ag}^{+}, \mathrm{Fe}^{3+}, \mathrm{K}^{+}, \mathrm{Ni}^{2+}$ and $\mathrm{Cr}^{3+}$ cations weakened the intensities compared with the blank suspension (Fig. 6B). Similarly, for 3 , in addition to $\mathrm{Fe}^{3+}$ ions and $\mathrm{Cr}^{3+}$ ions, the fluorescence intensity of other cationic suspensions was increased relative to the blank (Fig. 6D). It is not difficult to see from the figures that when $\mathrm{Fe}^{3+}$ ions are added, the strength of fluorescence of the above two compounds could be almost completely quenched. It follows that these two compounds showed selective recognition of $\mathrm{Fe}^{3+}$ ions in aqueous solution.

\section{Selective detection of $\mathrm{Fe}^{3+}$ ions}

Through previous reported literature, we had the fluorescence sensing experiment of $\mathrm{Fe}^{3+}$ with a good effect on quenching. Firstly, $2 \mathrm{~mL}$ of aqueous solvent suspensions containing crystal samples of 2 ( $2 \mathrm{mg}$ ) were treated ultrasonically for half an hour. Next, $\mathrm{Fe}\left(\mathrm{NO}_{3}\right)_{3}$ at $0.5 \mathrm{mmol} \mathrm{L}^{-1}(\mathrm{mM})$ was gradually added to it and its luminescence intensity was tested (the experimental steps for 3 are the same as those for 2; in addition, the concentration of $\mathrm{Fe}\left(\mathrm{NO}_{3}\right)_{3}$ in 3 was $\left.1 \mathrm{mM}\right) .{ }^{16}$ As depicted in 

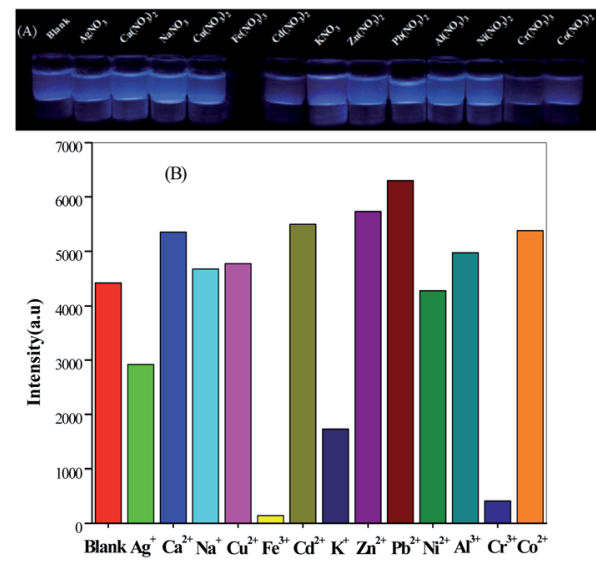
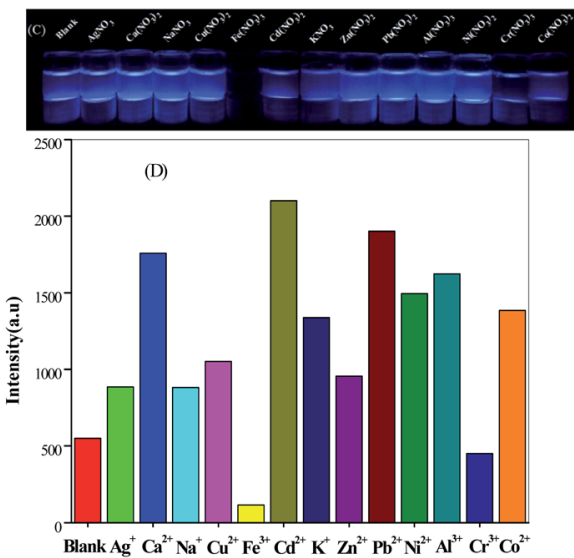

Fig. 6 Glow diagram under UV light irradiation $(\lambda=365 \mathrm{~nm})$ and luminescence response of compound $2(A$ and $B)$ and compound $3(C$ and $D)$ immersed in the presence of metal ion solutions.

Fig. 7A and C, the fluorescence intensities of 2 @ $\mathrm{Fe}^{3+}$ and 3 (a) $\mathrm{Fe}^{3+}$ stable suspensions were quenched, gradually decreasing with an increase in the concentration of $\mathrm{Fe}^{3+}$; moreover, the quenching efficiency was $82.67 \%$ when the $\mathrm{Fe}^{3+}$ concentration rose to $0.1500 \mathrm{mM}$ for 2 and the quenching efficiency was $69.74 \%$ for 3 when the $\mathrm{Fe}^{3+}$ concentration rose to $0.3243 \mathrm{mM}$. The consequent quenching could be quantitatively rationalized by the Stern-Volmer equation, $I_{0} / I=K_{\mathrm{sv}}[\mathrm{M}]+1\left(I_{0}\right.$ and $I$ are the luminescence intensities of 2 and 3 without and with the addition of the analyte, respectively). $K_{\mathrm{sv}}$ is the quenching constant, $[\mathrm{M}]$ is the molar concentration of $\left.\mathrm{Fe}^{3+}\right) .{ }^{17} K_{\mathrm{SV}}$ was calculated to be $3.06 \times 10^{5} \mathrm{M}^{-1}$ from the Stern-Volmer plots for 2 (Fig. 7B), and it showed a good linear relationship when the concentration was low $(0-0.0150 \mathrm{mM})$. Similarly, $K_{\mathrm{Sv}}$ was calculated to be $1.07 \times 10^{5} \mathrm{M}^{-1}$ for 3 at $0-0.0521 \mathrm{mM}$ (Fig. 7D). The mechanism of $\mathrm{Fe}^{3+}$ cation fluorescence quenching was that with the continuous addition of $\mathrm{Fe}^{3+}$, an interaction between the metal ion and the complex caused the metal ion to transfer charge, causing the ligand absorption of the excitation energy to dissipate in a non-radiative form, eventually leading to a decline in the fluorescence intensities or even quenching.

\section{Catalytic degradation of dyes under illumination}

Considering the high pore volume of compounds 2 and 3 , potential applications in the catalytic degradation of unused dye molecules under illumination were investigated. To check
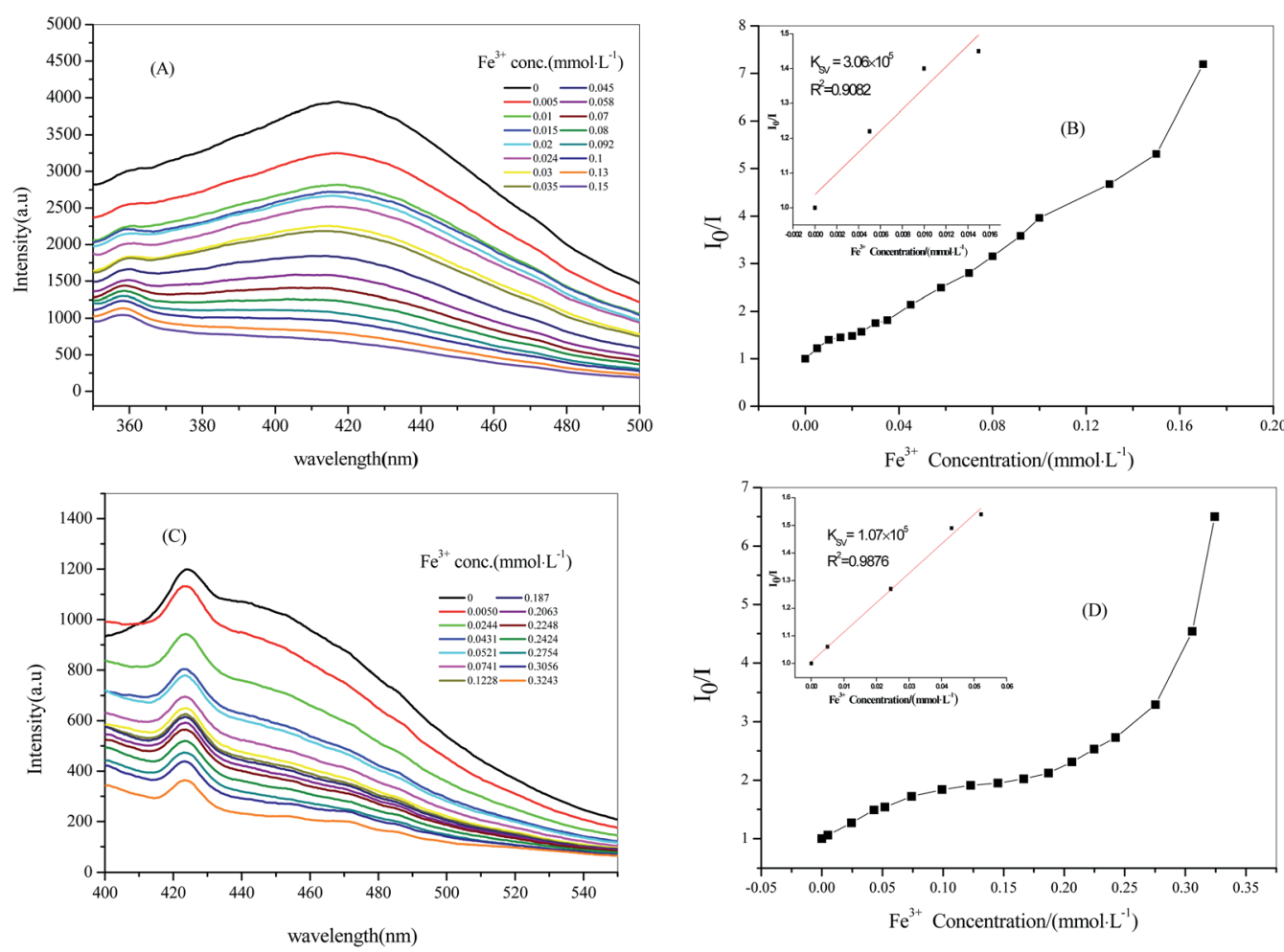

Fig. 7 Stern-Volmer plot of compound 2 with $0.5 \mathrm{mM} \mathrm{Fe}^{3+}$ solution (A) and (B), compound 3 with $1 \mathrm{mM} \mathrm{Fe} \mathrm{e}^{3+}$ solution (C) and (D). 


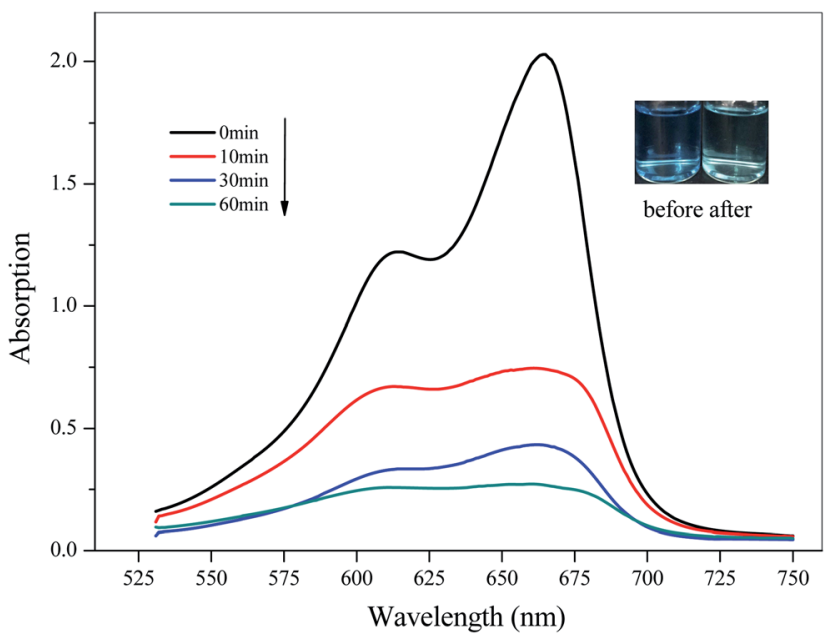

Fig. 8 Time-dependent UV-vis spectra of MB in water solution in the presence of 2 (the inserted photographs show the color change before and after dye degradation).

the adsorption ability of 2 towards different dyes, $10 \mathrm{mg}$ of compound 2 was added into various solutions of negatively charged Methyl Orange (MO), positively charged Methylene Blue (MB), and Rhodamine B (RhB) in water $\left(10 \mathrm{mg} \mathrm{L}^{-1}, 100\right.$ $\mathrm{mL}$ ), respectively, then magnetically stirred in the dark to achieve adsorption-dissociation equilibrium. The UV-vis spectra were recorded at different time intervals under the illumination of a xenon lamp. The research method for $\mathbf{3}$ was the same as that for 2. For 2, The UV-vis spectroscopic analyses and photographs before and after adsorption suggested that 2 could be used as a catalyst to degrade dye MB (Fig. 8), but there was no obvious effect for MO or RhB (ESI, Fig. S5 $†$ ). The results showed that $\mathbf{2}$ had good degradability for MB, mainly due to the interaction between the organic dyes and the composite framework. In addition, the degradation rate of MB solution was $88.70 \%$ after $60 \mathrm{~min}(65.64 \%$ at $10 \mathrm{~min})$. For 3, it could be seen that it showed adsorption for MO (ESI, Fig. S6 $\dagger$ ). The degradation rate

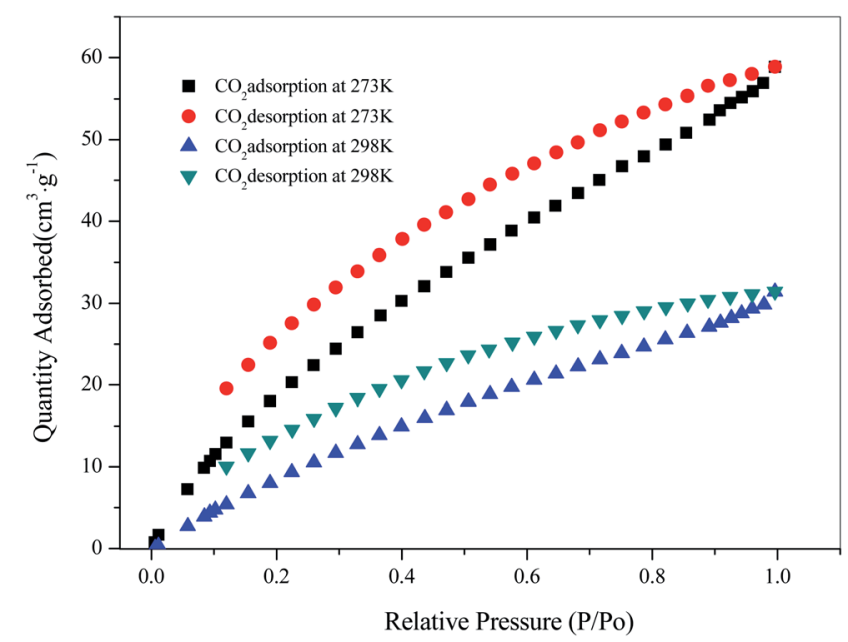

Fig. 9 Adsorption isotherms for $\mathrm{CO}_{2}$ at $273 \mathrm{~K}$ and $298 \mathrm{~K}$. of MO solution was $30.61 \%$ after $180 \mathrm{~min}$. By comparison, it was easy to see that 2 showed good degradation for MB and could selectively degrade $\mathrm{MB}$ in a short time; $\mathbf{3}$ had a degradation effect on MO.

\section{Gas adsorption of 3}

Since the structure of compound 3 had a large hole, the adsorption of $\mathrm{CO}_{2}$ and $\mathrm{CH}_{4}$ was carried out for 3 at temperatures of $273 \mathrm{~K}$ and $298 \mathrm{~K}$, respectively. Firstly, $80 \mathrm{mg}$ of the sample was vacuum dried at $353 \mathrm{~K}$ for 10 hours, and then subjected to a gas adsorption test at constant temperature. As shown in Fig. 9, the adsorption performance of 3 for $\mathrm{CO}_{2}$ was better at $273 \mathrm{~K}$, reaching $58.85 \mathrm{~cm}^{3} \mathrm{~g}^{-1}$, and the adsorption amount was $19.95 \mathrm{~cm}^{3} \mathrm{~g}^{-1}$ at $298 \mathrm{~K}$. In addition, the amount of adsorption of $\mathrm{CH}_{4}$ was $15.12 \mathrm{~cm}^{3} \mathrm{~g}^{-1}$ at $273 \mathrm{~K}$ (ESI, Fig. S7†). The Langmuir surface obtained by fitting its adsorption isotherms was $230.11 \mathrm{~m}^{2} \mathrm{~g}^{-1}$. The results showed that compound 3 had good adsorption capacity for $\mathrm{CO}_{2}$.

\section{Conclusions}

In summary, the synthesis and characterization of three compounds with $\mathrm{H}_{2} \mathrm{tmdb}$ ligands were reported. The polymer was analyzed using PXRD, IR, TGA and fluorescence. Among these, in compound 1 , two $2 \mathrm{D}$ layers were interlaced and interspersed, and then stacked to form a 3D structure. Compound 2 was a 4 -fold interpenetrating structure with spiral chains, and compound 3 was a 3 -fold interpenetrating structure. Compounds 2 and 3 had a significant sensitizing effect on the ECL signal: in particular, 2 could reach three times as high. Furthermore, 2 and 3 could be used as potential fluorescence materials for sensing $\mathrm{Fe}^{3+}$ ion with high selectivity and sensitivity. Simultaneously, experimental results for the catalytic degradation of dyes under illumination indicated that 2 could efficiently degrade $\mathrm{MB}$ and 3 could efficiently degrade MO. Moreover, 3 had good adsorption capacity for $\mathrm{CO}_{2}$.

\section{Conflicts of interest}

There are no conflicts to declare.

\section{Acknowledgements}

The authors gratefully acknowledge the financial support by the Science and Technology Development Planning of Jilin Province, China (No. 20170101098JC) and The 13th Five Science and Technology Research of Jilin Province Department of Education (No. JJKH20181174KJ).

\section{References}

1 (a) G. Ferey, Chem. Soc. Rev., 2008, 37, 191; (b) Y. Zhang and K. Chen, Inorg. Chem. Commun., 2013, 35, 1; (c) C. J. Zhang, M. S. Wang and G. C. Guo, Inorg. Chem. Commun., 2013, 35, 76; (d) B. Li, S. Q. Zhang, C. Ji, H. W. Hou and T. C. Mark, Cryst. Growth Des., 2012, 12, 5529; (e) K. Liu, 
X. Li, D. X. Ma, Y. Han, B. Y. Li, Z. Shi, Z. J. Li and L. Wang, Mater. Chem. Front., 2017, 1, 1982.

2 (a) A. Aijaz, E. Barea and P. K. Bharadwaj, Cryst. Growth Des., 2009, 9, 4480; (b) A. Aijaz, P. Lama, E. C. Sanudo, R. Mishra and P. K. Bharadwaj, New J. Chem., 2010, 34, 2502.

3 W. H. Jiang, H. Z. Zhang, G. F. Hou, D. S. Ma, B. Liu and Y. H. Yu, RSC Adv., 2017, 7, 45641.

4 N. N. Mao, P. Hu, F. Yu, X. Chen, G. L. Zhuang, T. L. Zhang and B. Li, CrystEngComm, 2017, 19, 4586.

5 X. J. Gao, M. X. Zheng, L. Qin, K. Shen and H. G. Zheng, Cryst. Growth Des., 2016, 16, 4711.

6 (a) Y. L. Liu, K. F. Yue and B. H. Shan, Inorg. Chem. Commun., 2012, 17, 30; (b) X. Zhao, J. Dou and D. Sun, Dalton Trans., 2012, 41, 1928; (c) R. L. Chen, X. Y. Chen and S. R. Zheng, Cryst. Growth Des., 2013, 13, 4428; (d) K. Liu, Y. Y. Sun, L. M. Deng, F. Cao, J. S. Han and L. Wang, J. Solid State Chem., 2018, 258, 24.

7 (a) D. K. Maity, K. Otake and S. Ghosh, Inorg. Chem., 2017, 56, 1581; (b) H. Q. Huang, X. Y. Cheng and T. Zhang, Inorg. Chem. Commun., 2016, 68, 21; (c) A. Husain, R. Parveen and P. Dastidar, Cryst. Growth Des., 2015, 15, 5075.

8 (a) B. Wisser, Y. Lu and C. Z. Janiak, Z. Anorg. Allg. Chem., 2007, 633, 1189; (b) R. Kieltyka, P. Englebienne and J. Fakhoury, J. Am. Chem. Soc., 2008, 130, 10040; (c) X. Zhang, L. Hou and B. Liu, Cryst. Growth Des., 2013, 13, 3177.
9 (a) J. H. Cui, Y. Z. Li, Z. J. Guo and H. G. Zheng, Cryst. Growth Des., 2012, 12, 3610; (b) L. M. Fan, W. L. Fan, B. Li, X. Z. Liu, X. Zhao and X. T. Zhang, Dalton Trans., 2015, 44, 2380.

10 (a) Y. Fan, C. D. Si, C. Hou, X. Q. Yao, D. C. Hu, Y. X. Yang and J. C. Liu, Polyhedron, 2015, 98, 64; (b) H. H. Li, W. Shi, K. N. Zhao, Z. Niu, H. M. Li and P. Cheng, Chem.-Eur. J., 2013, 19, 3358; (c) T. P. Hu, B. H. Zheng, X. Q. Wang and X. N. Hao, CrystEngComm, 2015, 17, 9348.

11 (a) J. F. Song, S. Z. Li, R. D. Zhou, J. Shao, X. M. Qiu, Y. Y. Jia, J. Wang and X. Zhang, Dalton Trans., 2016, 45, 11883; (b) Z. Li, CrystEngComm, 2011, 13, 1984.

12 L. S. Meng, L. Zhao, C. J. Zhao and X. Lin, J. Mol. Struct., 2019, 1179, 425.

13 F. F. Wu, Y. Zhou, H. Zhang, R. Yuan and Y. Q. Chai, Anal. Chem., 2018, 90, 2263.

14 G. M. Sheldrick, Acta Crystallogr., Sect. A: Found. Crystallogr., 2008, 64, 112.

15 (a) F. P. Huang, Z. M. Yang, P. F. Yao, Q. Yu, J. L. Tian, H. D. Bian, S. P. Yan, D. Z. Liao and P. Cheng, CrystEngComm, 2013, 15, 2657; (b) Y. Su, S. Zhang, Y. Li, A. Z. Zhu and Q. Meng, Cryst. Growth Des., 2007, 7, 1277.

16 (a) L. M. Deng, Y. W. Zhang, D. Zhang, S. S. Jiao, J. X. Xu, K. Liu and L. Wang, CrystEngComm, 2019, 21, 6056; (b) X. Liu, L. Zhao, C. J. Zhao, L. S. Meng and C. Liu, J. Mol. Struct., 2019, 1188, 238.

17 S. W. Thomas, G. D. Joly and T. M. Swager, Chem. Rev., 2007, 107, 1339. 